\title{
Endovascular treatment of thoracic aortic pseudoaneurysm due to brucellosis: a rare case report
}

\author{
Shuai Wang ${ }^{1}$, Qi Wang ${ }^{1}$, Han Liu², Siqiao Sun ${ }^{1}$, Xiwei Sun¹, Yang Zhang ${ }^{1}$, Zhongying Wang ${ }^{1}$ and Zhihua Cheng ${ }^{\text {** }}$
}

\begin{abstract}
Background: Arterial damage is a known complication of brucellosis, but the occurrence of a thoracic aortic pseudoaneurysm secondary to brucellosis has not been previously reported.

Case presentation: A 65-year-old Chinese man presented with a pseudoaneurysm in the descending segment of the thoracic aorta that caused symptoms of chest pain and intermittent fever. He was diagnosed with a thoracic aortic pseudoaneurysm secondary to brucellosis based on a positive brucella serology test (standard-tube agglutination test) and imaging examination (computed tomography angiography). Anti-brucellosis treatment and covered stent graft implantation were attempted to eliminate the brucellosis and pseudoaneurysm, respectively, and were ultimately successful, with no symptoms after 6 months of follow-up.
\end{abstract}

Conclusion: Endovascular repair may be effective and safe for treating a thoracic aortic pseudoaneurysm resulting from brucellosis.

Keywords: Brucellosis, Pseudoaneurysm, Thoracic aorta, Stent implantation

\section{Background}

Brucellosis is a zoonotic infection that most commonly occurs in Middle Eastern, Mediterranean, and East Asian countries. Nearly 200 cases are reported every year in Italy, [1] and nearly 4000 cases are reported every year in China, with more than half of the cases occurring in the northeast and northern regions, including the inner Mongolia autonomous region and Heilongjiang and Jilin provinces. The reservoir hosts include sheep, cattle, and swine, and transmission from sheep is the most common way of contraction in China [2]. Humans become infected with the disease through ingestion of contaminated milk products or meat or through direct contact via the mucous membranes. Certain professions, such as breeder, butcher, dairyman, and kitchen employee, are associated with an increased risk of contracting the disease [2]. The main clinical presentations include undulant fever, night sweats, and joint pain in the acute stage [3]. These symptoms as well as joint damage, tendon contracture,

\footnotetext{
* Correspondence: 441980580@qq.com

${ }^{1}$ Department of Vascular Surgery, the First Hospital of Jilin University, Xinmin

Street 71, Changchun, Jilin, China

Full list of author information is available at the end of the article
}

meningitis, orchitis, and epididymitis are all very common in the chronic stage. Meanwhile, damage to the cardiovascular, digestive, and respiratory systems is occasionally observed. More than $75 \%$ of deaths related to brucellosis occurred due to endocarditis [3, 4]. Pseudoaneurysms in peripheral arteries have been reported in a few cases, [5-7] but there has been no report of the occurrence of a thoracic aortic pseudoaneurysm secondary to brucellosis. Here, we describe a rare case of a brucellosis-induced thoracic aortic pseudoaneurysm and discuss the treatment procedure applied for this patient.

\section{Case presentation}

A 65-year-old Chinese man was admitted to the First Hospital of Jilin University complaining of intermittent fever for 2 months with the highest temperature reaching $40{ }^{\circ} \mathrm{C}$ and chest pain for 10 days. The patient had no history of drug abuse, invasive examination, thoracic aortic surgery, or trauma. Upon physical examination, the patient presented with low-grade fever with normal blood pressure, heart rate, and heart rhythm. Additional imaging examination via computed tomography angiography (CTA, (Fig. 1) revealed the formation of a pseudoaneurysm with a 

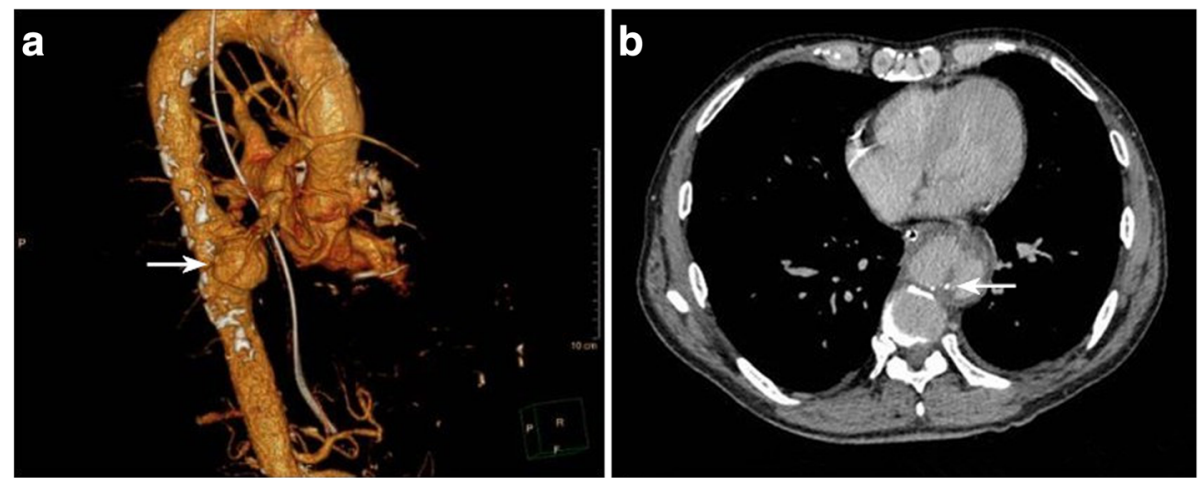

Fig. 1 Computed tomography angiography (CTA): a. The pseudoaneurysm was ound in the descending segment of the thoracic aorta, with a maximal diameter of $54 \mathrm{~mm}$ (arrow). b. Arteriosclerotic plaques were observed in the artery wall (arrow)

maximal diameter of $54 \mathrm{~mm}$ in the descending segment of the thoracic aorta. Electrocardiogram (ECG) showed normal sinus rhythm. Transthoracic echocardiography (TTE) was performed and showed mild mitral insufficiency without valvular vegetation. On additional laboratory tests, the C-reactive protein (CRP) level was $106 \mathrm{mg} / \mathrm{L}$, the erythrocyte sedimentation rate (ESR) was $97 \mathrm{~mm} / \mathrm{h}$, the white blood cell count (WBC) was $7.6 \times 10^{12} / \mathrm{L}$ with $83 \%$ neutrophils, and the hemoglobin $(\mathrm{Hb})$ level was $106 \mathrm{~g} / \mathrm{L}$. The results of neurological and cardiovascular examinations were normal, and the patient had no significant medical history of hypertension, heart diseases, diabetes mellitus, blood transfusion, genital ulcer, and/or skin rash. Therefore, it seemed unlikely that the case was caused by complications of these diseases. However, the patient recounted that he had been employed in a family owned restaurant and exposed to cattle and raw meat for 2 years since he had retired from being a sailor 4 years previously. Considering this information, a blood bacterial culture was ordered. A definitive diagnosis was made by isolating the brucella in the blood culture, and the finding on the standard-tube agglutination test (SAT) was 1:400, which corresponded to a strong positive result. In view of an active brucellosis infection and the high vascular inflammatory reaction that can cause a series of complications if surgery or endovascular treatment were to be performed, a combination of anti-brucellosis treatment with $450 \mathrm{mg}$ rifampin twice a day orally and $200 \mathrm{mg}$ doxycycline once a day orally was started immediately. We advised the patient to continue the treatment for at least 6 months. However, the patient presented with aggravated chest pain and mild hemoptysis (bright red, nearly $10 \mathrm{ml}$ ) without obvious cause 2 days later, which were considered the result of pseudoaneurysm rupture and hemorrhage into the pulmonary alveoli. To minimize the risks of morbidity and mortality in the repair of the thoracic aortic pseudoaneurysm, the Tag covered stent graft (W. L. Gore \& Associates, USA) was implanted to isolate the pseudoaneurysm. Intraoperatively, a $15-\mathrm{cm}, 6 \mathrm{~F}$ sheath (Terumo Corporation, Japan) was advanced into the right common femoral artery in a retrograde fashion. The pseudoaneurysm was viewed on digital subtraction angiography (DSA) by a pigtail catheter (Fig. 2). Then a $28-\mathrm{cm}, 22 \mathrm{~F}$ sheath (W. L. Gore \& Associates, USA) was advanced, and a $31 \mathrm{~mm} \times 150 \mathrm{~mm}$ Tag covered stent graft (W. L. Gore \& Associates, USA) was implanted to isolate the pseudoaneurysm through a Lunderquist extra stiff wire guide (Cook Medical Inc., USA). Finally, the angiography showed no contrast medium overflow in the thoracic aorta (Fig. 2). Postoperatively, the anti-brucellosis treatment was continued, and the symptoms disappeared gradually over the first week. At the 24th week follow-up, the SAT result was 1:50, which corresponded to a negative result. The patient continued the anti-brucellosis treatment for 2 more weeks, and at the 26th week follow-up, the SAT was negative and the patient was well and asymptomatic.

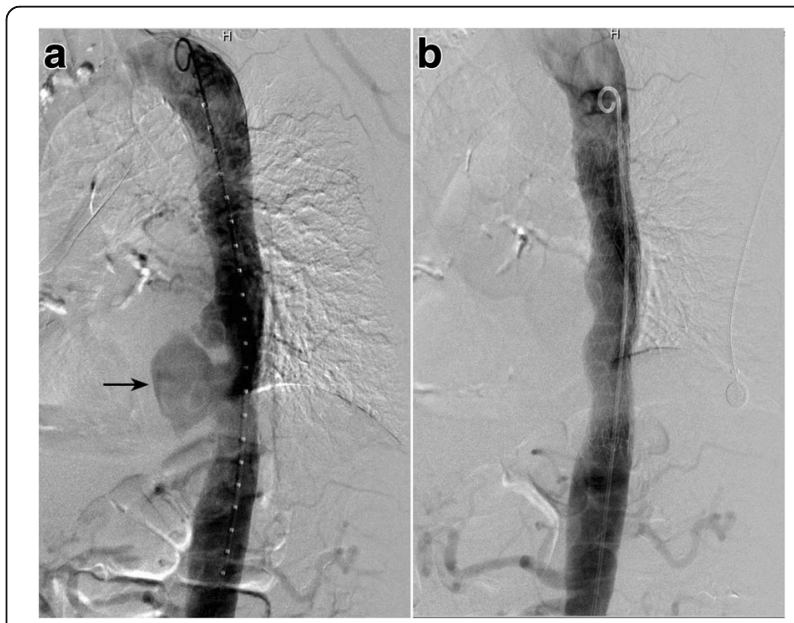

Fig. 2 Digital subtraction angiography (DSA): a. The pseudoaneurysm was revealed by contrast medium overflow (arrow). b. Angiography showed no contrast medium overflow in the thoracic aorta after treatment 


\section{Discussion}

Brucella can infect endothelial cells and induce a severe inflammatory response, leading to possible cardiovascular complications. In the inflammatory response, the pathogenic mechanism is suggested to involve endothelial activation in response to brucella infection, with upregulation of adhesion molecules and secretion of proinflammatory chemokines [8]. Vascular complications of brucellosis are rare, but include aneurysm in the peripheral arteries (aorta, brachial, tibioperoneal, mesenteric, and cerebral arteries) and venous and arterial thrombosis with or without underlying endocarditis [9-15]. Although rare, such vascular complications are so deadly they are the primary cause of death related to brucellosis. Pseudoaneurysm secondary to brucellosis is extremely rare in the peripheral arteries, but it is a very severe and dangerous complication [5-7]. In other case studies, it has been reported that mycotic pseudoaneurysm usually is due to trauma to the arterial wall with subsequent contamination [6, 16-21]. The arterial segment might be disrupted when an invasive infection is able to directly lodge in the artery or the vasa vasorum, especially with an intimal defect in the arterial wall such as an arteriosclerotic plaque $[6,19,20]$. In our case, the arteriosclerotic plaques were on CTA imaging.(Fig. 1) Due to the arteriosclerotic plaques and damage to the arterial endothelium, the medial layer was exposed to the bloodstream. Based on the physiological and pathological processes, brucella can easily destroy and even penetrate the arterial wall.

Generally, most cases of thoracic aortic pseudoaneurysms in the hospital settings occur following thoracic aortic surgery or trauma and are associated with high mortality rates [22]. Thus, urgent treatment of the thoracic aorta pseudoaneurysm is needed. Compared with open surgery, the endovascular treatment is more likely to minimize the operative wound, hospital stay, and peri-operative mortality [23]. In view of these factors, we performed the minimally invasive operation of implanting a coated stent graft and achieved an ideal outcome in our case. Management of Brucella-induced pseudoaneurysm involves resection of the affected artery and endovascular stenting together with long-term anti-brucellosis treatment. Despite the known hepatotoxicity, neurotoxicity, and reproductive toxicity, rifampin, doxycycline, and streptomycin are the basic drugs used for anti-brucellosis treatment clinically. Without a normative anti-brucellosis treatment, the patient would be more likely to suffer a poor prognosis [24].

\section{Conclusions}

In conclusion, the present case may be the first reported case of Brucella-induced thoracic aortic pseudoaneurysm and was successfully managed by endovascular treatment. However, this case has some limitations: 1. the follow-up time was ony 6.5 months; 2 . the Brucella- infected arterial wall and tissue were not removed; and 3. the diagnosis was based on a serological test (SAT) and imaging examination (CTA) without pathological analysis. Thus, a case series study is needed to facilitate a systematic diagnosis and formulate treatment recommendations for thoracic aortic pseudoaneurysm caused by brucellosis.

\section{Abbreviations \\ CRP: C-reactive protein; CTA: Computed tomography angiography; DSA: Digital subtraction angiography; ECG: Electrocardiogram; ESR: Erythrocyte sedimentation rate; Hb: Hemoglobin; SAT: Standard-tube agglutination test; TTE: Transthoracic echocardiogram; WBC: White blood cell count}

\section{Acknowledgments}

We thank Dr. Sean X. Luo (Department of Vascular Surgery, the First Hospital of Jilin University, Changchun, Jilin, China) and Medjaden Bioscience Co., Ltd. (Hongkong, China) for assistance of medical editing and writing.

Funding

Not applicable.

\section{Availability of data and materials}

We are sorry that the data will not be shared because there is no a website or media to save and show the data in our hospital.

\section{Authors' contributions}

SW participated in the design and coordination of the study and drafted the manuscript. QW drafted the manuscript, collected data and collected background information. HL revised the manuscript, collected data and collected background information. SQS and XWS performed the surgery. YZ and ZYW participated in the interpretation of data. ZHC participated in the design of the study and interpretation of data and drafted the manuscript. All authors read and approved the final manuscript.

\section{Competing interests}

The authors declare that they have no competing interests.

\section{Consent for publication}

Written informed consent was obtained from the patient for publication of this case report and any accompanying images.

Ethics approval and consent to participate

Not applicable.

\section{Author details}

${ }^{1}$ Department of Vascular Surgery, the First Hospital of Jilin University, Xinmin Street 71, Changchun, Jilin, China. ${ }^{2}$ Department of Respiration, the First Hospital of Jilin University, Xinmin Street 71, Changchun, Jilin, China.

Received: 7 December 2016 Accepted: 22 May 2017

Published online: 02 June 2017

References

1. Colomba C, Siracusa L, Rubino R, Trizzino M, Scarlata F, Imburgia C, et al. A case of Brucella endocarditis in association with subclavian artery thrombosis. Case rep Infect dis. 2012;581489

2. Cui BY. Epidemic surveillance and control of brucellosis in China. Disease Surveillance. 2007;22(10):649-51.

3. Pappas G, Akritidis N, Bosilkovski M, Tsianos E. Brucellosis. N Engl J med. 2005:352(22):2325-36

4. Reguera JM, Alarcon A, Miralles F, Pachon J, Juarez C, Colmenero JD. Brucella endocarditis: clinical, diagnostic, and therapeutic approach. Eur J Clin Microbiol Infect dis. 2003;22(11):647-50

5. Harman $\mathrm{M}$, Irmak H, Arslan $\mathrm{H}$, Arslan U, Kayan M. Popliteal artery pseudoaneurysm: a rare complication of brucellosis. J Clin Ultrasound. 2004;32(1):33-6.

6. Ustuner E, Erden A, Fitoz S, Erden I, Sancak T. Deep femoral artery pseudoaneurysm due to brucellosis. J Ultrasound med. 2001;20(12):1353-6. 
7. Bergeron P, Gonzales-Fajardo J, Mangialardi N, Courbier R. False aneurysm of the abdominal aorta due to Brucella suis. Ann Vasc Surg. 1992;6(5):460-3.

8. Ferrero MC, Bregante J, Delpino MV, Barrionuevo P, Fossati CA, Giambartolomei GH, et al. Proinflammatory response of human endothelial cells to Brucella infection. Microbes Infect. 2011;13(10):852-61.

9. Gelfand MS, Kaiser AB, Dale WA. Localized brucellosis: popliteal artery aneurysm, mediastinitis, dementia, and pneumonia. Rev Infect dis. 1989; 11(5):783-8.

10. Zaidan R, Al Tahan AR. Cerebral venous thrombosis: a new manifestation of neurobrucellosis. Clin Infect dis. 1999;28(2):399-400.

11. Yrivarren JL, Lopez LR. Cryoglobulinemia and cutaneous vasculitis in human brucellosis. J Clin Immunol. 1987;7(6):471-4.

12. Odeh M, Pick N, Oliven A. Deep venous thrombosis associated with acute brucellosis-a case report. Angiology. 2000;51(3):253-6.

13. Andrew WK. An unusual cause of deep venous thrombosis of the lower limb. S Afr med J. 2000;90(1):42.

14. Caylan R, Keske S, Durmaz T, Keles T, Tasyaran MA. A case of Brucella endocarditis in association with superficial femoral artery thrombus. Trop Dr. 2009:39(4):251-2.

15. Prasad S, Lingadakai R, Chethan $\mathrm{K}$, Abdul Z. Superior mesenteric artery syndrome secondary to brucellosis - a case report. Indian J Surg. 2010;72(3):265-7.

16. Johansen K, Devin J. Mycotic aortic aneurysms. Arch Surg. 1983;118(5):583-8.

17. Trevisani MF, Ricci MA, Michaels RM, Meyer KK. Multiple mesenteric aneurysms complicating subacute bacterial endocarditis. Arch Surg. 1987; 122(7):823-4.

18. Dean RH, Waterhouse G, Meacham PW, Weaver FA, O'Neil JA Jr. Mycotic embolism and embolomycotic aneurysms. Neglected lessons of the past. Ann Surg. 1986;204(3):300-7.

19. Togan T, Ciftci O, Turan H, Narci H, Gullu H, Arslan H. Could there be an association between chronic brucellosis and endothelial damage? I Infect dev Ctries. 2015:9(1):48-54.

20. Gursoy MO, Tursun I, Alpua M, Haykir Solay A, Tokat Cobanli M, Demirtas H, et al. Brucellosis impairs endothelial functions in chronic symptomatic patients without overt cardiac involvement. Turk Kardiyol Dern Ars 2015 43(3): 242-249.

21. Cheng Z, Luo SX, Sun $X$, Sun $S$, Wang $Z$, Jiang $Y$, et al. Surgical treatment of syphilitic superficial femoral artery aneurysm: a rare case report. BMC Infect dis. 2015;15:540.

22. Inaba Y, Ito T, Hayashi S, lida Y, Misumi T, Shimizu H. Surgical strategy for thoracic aortic Pseudoaneurysm with sternal adherence. Ann Vasc dis. 2016; 9(3):235-9.

23. Goodney PP, Travis L, Lucas FL, Fillinger MF, Goodman DC, Cronenwett JL, et al. Survival after open versus endovascular thoracic aortic aneurysm repair in an observational study of the Medicare population. Circulation. 2011;124(24):2661-9.

24. Solis Garcia del Pozo J, Solera J. Systematic Review and Meta-Analysis of Randomized Clinical Trials in the Treatment of Human Brucellosis. PLoS One. 2012; 7(2): e32090.

\section{Submit your next manuscript to BioMed Central and we will help you at every step:}

- We accept pre-submission inquiries

- Our selector tool helps you to find the most relevant journal

- We provide round the clock customer support

- Convenient online submission

- Thorough peer review

- Inclusion in PubMed and all major indexing services

- Maximum visibility for your research

Submit your manuscript at www.biomedcentral.com/submit

) Biomed Central 